\title{
Steroid 5 alpha-reductase 2 enzyme variants, biomass exposure and tobacco use in Mexican patients with prostate cancer
}

\author{
JESUS ROLANDO DELGADO-BALDERAS ${ }^{1 *}$, HUGO LEONID GALLARDO-BLANCO ${ }^{2 *}$, \\ JUAN FELIPE YEE-DE LEÓN ${ }^{3 *}$, ANA MARIA RIVAS-ESTILLA ${ }^{1}$, BRENDA SOTO-GARCÍA ${ }^{3}$, \\ DIANA ARÁIZ-HERNÁNDEZ ${ }^{3}$, RAQUEL GARZA-GUAJARDO ${ }^{4}$, MELISSA NÁÑEZ-MARÍN $^{4}$, \\ DAVID HERNÁNDEZ-BARAJAS ${ }^{5}$, ALDO MISSAEL GARCÍA-BAILÓN ${ }^{6}$, \\ GUILLERMO VÍZCARRA-MATA ${ }^{6}$, MARCO ALBERTO OCAÑA-MUNGUÍA ${ }^{6}$, \\ LAURO SALVADOR GÓMEZ-GUERRA ${ }^{6}$ and CELIA NOHEMÍ SÁNCHEZ-DOMÍNGUEZ
}

\begin{abstract}
Departments of ${ }^{1}$ Biochemistry and Molecular Medicine and ${ }^{2}$ Genetics, School of Medicine, Universidad Autónoma de Nuevo León, Monterrey 64460, Mexico; ${ }^{3}$ Delee Corp., Mountain View, CA 94041, USA; ${ }^{4}$ Pathological Anatomy and Cytopathology Service; ${ }^{5}$ Oncology Service, University Center Against Cancer; ${ }^{6}$ Urology Service, 'Dr. José Eleuterio González’ University Hospital, Universidad Autónoma de Nuevo León, Monterrey 64460, Mexico
\end{abstract}

Received April 3, 2020; Accepted July 31, 2020

DOI: $10.3892 / 01.2020 .12124$

\begin{abstract}
The presence of the genetic variants of the steroid 5 -alpha reductase 2 enzyme, which is encoded by the SRD5A2 gene, has been associated with an increased risk of developing prostate cancer among certain ethnic groups. However, these molecular studies have not been conducted on the Mexican population. The analysis of the genetic variants, rs9282858 and rs523349, was performed in 101 males with prostate cancer and 100 healthy controls classified as males without prostate abnormalities $(n=60)$ and males with benign prostatic hyperplasia $(n=40)$, to identify a probable association with this cancer type in the Northeast Mexican population.
\end{abstract}

Correspondence to: Dr Lauro Salvador Gómez-Guerra, Urology Service, 'Dr. José Eleuterio González' University Hospital, Universidad Autónoma de Nuevo León, Francisco I. Madero Avenue and Dr. José Eleuterio González Avenue, Monterrey 64460, Mexico E-mail: laurogomez@hotmail.com

Dr Celia Nohemí Sánchez-Domínguez, Department of Biochemistry and Molecular Medicine, School of Medicine, Universidad Autónoma de Nuevo León, Francisco I. Madero Avenue and Dr. Eduardo Aguirre Pequeño Street, Monterrey 64460, Mexico E-mail: celia.sanchezdm@uanl.edu.mx

*Contributed equally

Abbreviations: SRD5A2 gene, steroid 5 alpha-reductase 2 gene; A49T, Alanine49Threonine; V89L, Valine89Leucine; A, adenine; $\mathrm{G}$, guanine; $\mathrm{C}$, cytosine; $\mathrm{PCR}$, polymerase chain reaction; Ala, alanine; Thr, threonine; Val, valine; Leu, leucine; OR, Odds ratio; EDTA, ethylenediaminetetraacetic acid; IQR, interquartile range

Key words: prostate cancer, steroid 5 alpha-reductase 2 enzyme, A49T (rs9282858), V89L (rs523349), biomass exposure
An association was identified between prostate cancer and biomass exposure $[\mathrm{P}=0.012$; odds ratio $(\mathrm{OR}), 2.89$; confidence interval $(\mathrm{CI})=1.21-6.88]$ and tobacco use $(\mathrm{P}=0.028 ; \mathrm{OR}=1.88$; $\mathrm{CI}=1.07-3.31$, while no association was observed between cancer development and the rs9282858 variant, or between a protective effect and the rs 523349 variant. Notably, an association was identified between rs523349 and biomass exposure $(\mathrm{P}=0.013, \mathrm{OR}=3.17 ; \mathrm{CI}=1.23-8.17$ for the $\mathrm{G}$ risk allele, and $\mathrm{OR}=0.32, \mathrm{CI}=0.12-0.81$ for the $\mathrm{C}$ protective allele) using the dominant genetic model. To the best of our knowledge, the present study was the first of its type to investigate the Mexican population with prostate cancer.

\section{Introduction}

Prostate cancer (PCa) is the second most common type of malignancy among males worldwide; in 2018, the World Health Organization estimated more than 1.3 million new prostate cancer cases and over 359,000 mortalities due to this disease (1). In Mexico, $\mathrm{PCa}$ is the most common and fatal cancer type among males, accounting for $>10,000$ new cases and 5,000 mortalities during the same period of time (1). PCa is usually diagnosed in the fifth decade of life, with a variable rate of progression that largely depends on genetic and environmental factors, as well as the patient's lifestyle (2).

Androgens are necessary for the correct development and function of the prostate gland; however, they also serve a critical role in driving the growth of early-stage $\mathrm{PCa}$ (3). Androgen action, mediated by the androgen receptor (AR), leads to the activation of target genes that stimulate the proliferation and inhibit the apoptosis of cancer cells $(3,4)$. Free testosterone diffuses across the membranes of target cells located within the prostatic tissue acting as a substrate for the steroid 5 alphareductase 2 enzyme (encoded by the SRD5A2 gene), which converts testosterone to dihydrotestosterone (DHT), a more potent metabolite that activates the AR (5). Once activated, 
the AR is translocated to the nucleus where it dimerizes with another AR and activates target genes that promote cell proliferation $(3,4,6,7)$ (Fig. 1).

Certain DNA variants in the genomic sequence of the SRD5A2 gene alter the catalytic activity of steroid 5-alpha reductase 2, which may increase the risk of PCa development (8-11). In this context, certain variants have been associated with an increased risk of developing $\mathrm{PCa}$, including TA dinucleotides in the 3'-UTR region $(12,13)$, rs9332964 (14,15), rs928258 (9) and rs523349 (16,17). The rs928258 and rs523349 variants have been screened mainly across different ethnic groups.

The rs9282858 (p.Ala49Thr or A49T) variant results from a single nucleotide substitution, a $\mathrm{G}$ by an A (GCC/ACC), causing an amino acid change from an alanine to a threonine. It has been reported that this change increases the catalytic activity of the enzyme by 5 -fold $(14,18)$. The ENSEMBL database reports this variant as a) benign in ClinVar, b) deleterious in SIFT, c) benign in PolyPhen, and d) likely benign in CADD (http://www.ensembl.org/Homo_ sapiens/Variation/Mappings?db=core; $r=2: 31580256-31581256$; $\mathrm{v}=\mathrm{rs}$ 9282858; vdb=variation; $\mathrm{ff}=57248637)$.

By contrast, the rs523349 (p.Val89Leu or V89L) variant results from a single nucleotide substitution, a $C$ by a $G$ (CTA/GTA), causing an amino acid change from a valine to a leucine. It has been reported that this change reduces the enzyme activity by $30 \%(14,16,19)$. The ENSEMBL database reports this variant as a) benign in ClinVar, b) tolerated substitution in SIFT, c) benign in PolyPhen, and d) likely benign in CADD (http://www.ensembl.org/Homo_ sapiens/Variation/Mappings?db=core; $\mathrm{r}=2: 31580136-31581136 ; \mathrm{v}=\mathrm{rs}$ 523349; $\mathrm{vdb}=$ variation; $\mathrm{vf}=54157055)$.

As in a number of other diseases, the molecular findings on populations of European descent cannot be assumed for all populations. To implement a precision medicine model, molecular studies must be performed in diverse ethnic groups of interest. Genomic and genetic data of populations of non-European descendants remain under represented (20).

The Mexican population is genetically diverse (21); therefore, a more detailed study of the population structure alongside geographical data is required to assess the frequency and prevalence of genetic diseases in native and Mexican-mestizo populations (21-23). In diseases, including prostate cancer, this information may aid in diagnosis, prognosis, and treatment $(21,22)$.

In Mexico, $\mathrm{PCa}$ is a national health problem, but molecular studies regarding $\mathrm{PCa}$ in this population are limited. Certain studies with regard to $A R, V D R$ (24), VEGF (25), ATP6, and ND3 (26) genetic variants have been made. However, to the best of our knowledge, there are no previous reports that analyze the presence of the genetic variants, A49T and V89L, of the steroid 5 alpha-reductase 2 enzyme in the Mexican-mestizo population. Therefore, a molecular analysis of these genetic variants and examination of relevant clinical data was performed in the present study to identify a possible association with the development of PCa on the Mexican-mestizo population.

\section{Materials and methods}

Study design. The protocol was approved by the Ethics and Research Committee of the School of Medicine of the
Universidad Autónoma de Nuevo León (no. UR16-00007). This protocol was performed by the Biochemistry and Molecular Medicine Department using convenience sampling. Participants were enrolled between January 2018 and December 2019 through the Urology and Oncology Services from the 'Dr. José Eleuterio González' University Hospital of the Universidad Autónoma de Nuevo León, and each patient provided written informed consent to participate in the present study.

Recruited participants were classified into three groups according to subsequent analyses: $P C a$ cases $(n=101$; median age, 70 years; age range, 64.5-75.0 years) and non-PCa subjects $(n=100$; median age, 58 years; age range, 48-67 years) composed of males without prostate abnormalities $(n=60)$ and subjects with benign prostatic hyperplasia (BPH; $n=40)$. The PCa cases were males diagnosed with $\mathrm{PCa}$ regardless of the time elapsed since the diagnosis or their treatment status.

Blood samples were collected in a $6 \mathrm{ml}$ BD Vacutainer tube with EDTA (Becton-Dickinson). Demographic data of clinical importance were collected, and the database was prepared. PSA levels were analyzed only for the $\mathrm{PCa}$ and $\mathrm{BPH}$ groups.

DNA extraction protocol. Each blood sample was centrifuged at 3,857 $\mathrm{g}$ for $10 \mathrm{~min}$ at room temperature. From the buffy coat, DNA extraction was performed using a previously reported method with TSNT lysis buffer (composed of $1 \%$ Triton, $1 \%$ sodium dodecyl sulfate, $100 \mathrm{mM} \mathrm{NaCl}$, $10 \mathrm{mM}$ Tris-HCl pH 8.0 and $1 \mathrm{mM}$ EDTA) and followed by a phenol-chloroform extraction step $(27,28)$. The DNA was precipitated from aqueous phase with ethanol and quantified using NanoDrop 1000 (Thermo Fisher Scientific, Inc.) and its quality was verified through absorbance ratios (260/280 and 260/230 nm) and agarose gel electrophoresis.

Genotyping. Genotyping assays were performed using the commercial TaqMan SNP Genotyping Assays probes C__27532228_20 and C___2362601_10 (Thermo Fisher Scientific, Inc.) for the A49T (rs9282858) and V89L (rs523349) gene variants of the SRD5A2 gene (NM_000348.3), respectively.

DNA samples were processed using a StepOnePlus ${ }^{\mathrm{TM}}$ Real-Time PCR system (Thermo Fisher Scientific, Inc.). Each PCR reaction was performed using $5 \mu$ l SensiFAST $^{\text {тм }}$ Hi-Rox Genotyping kit (Bioline; Meridian Bioscience, Inc.), $0.5 \mu 1$ probe, $5 \mu \mathrm{l}$ nuclease-free water, and $3 \mu \mathrm{l}$ DNA (300 ng).

The amplification program used was the following: Pre-PCR read $60^{\circ} \mathrm{C} / 30 \mathrm{sec}$, holding stage $95^{\circ} \mathrm{C} / 10 \mathrm{~min}$, cycling stage: i) $95^{\circ} \mathrm{C} / 15 \mathrm{sec}$; ii) $60^{\circ} \mathrm{C} / 1 \mathrm{~min}$, and post-PCR read $60^{\circ} \mathrm{C} / 30 \mathrm{sec}$. The results were analyzed using the StepOne ${ }^{\mathrm{TM}}$ software v.2.2.2, (Thermo Fisher Scientific, Inc.).

Statistical analysis. Gene analysis was conducted using the Golden Helix SNP \& Variation Suite 8.8.3 program (Golden Helix, Inc.). The DNA variants were analyzed for deviation from the Hardy-Weinberg Equilibrium (HWE) using the Fisher's exact test $(\mathrm{P}<0.05$ was considered to indicate a statistically significant difference and HW disequilibrium). The genetic association study was performed using the dominant and recessive gene models in order to assess odds ratios (ORs), 


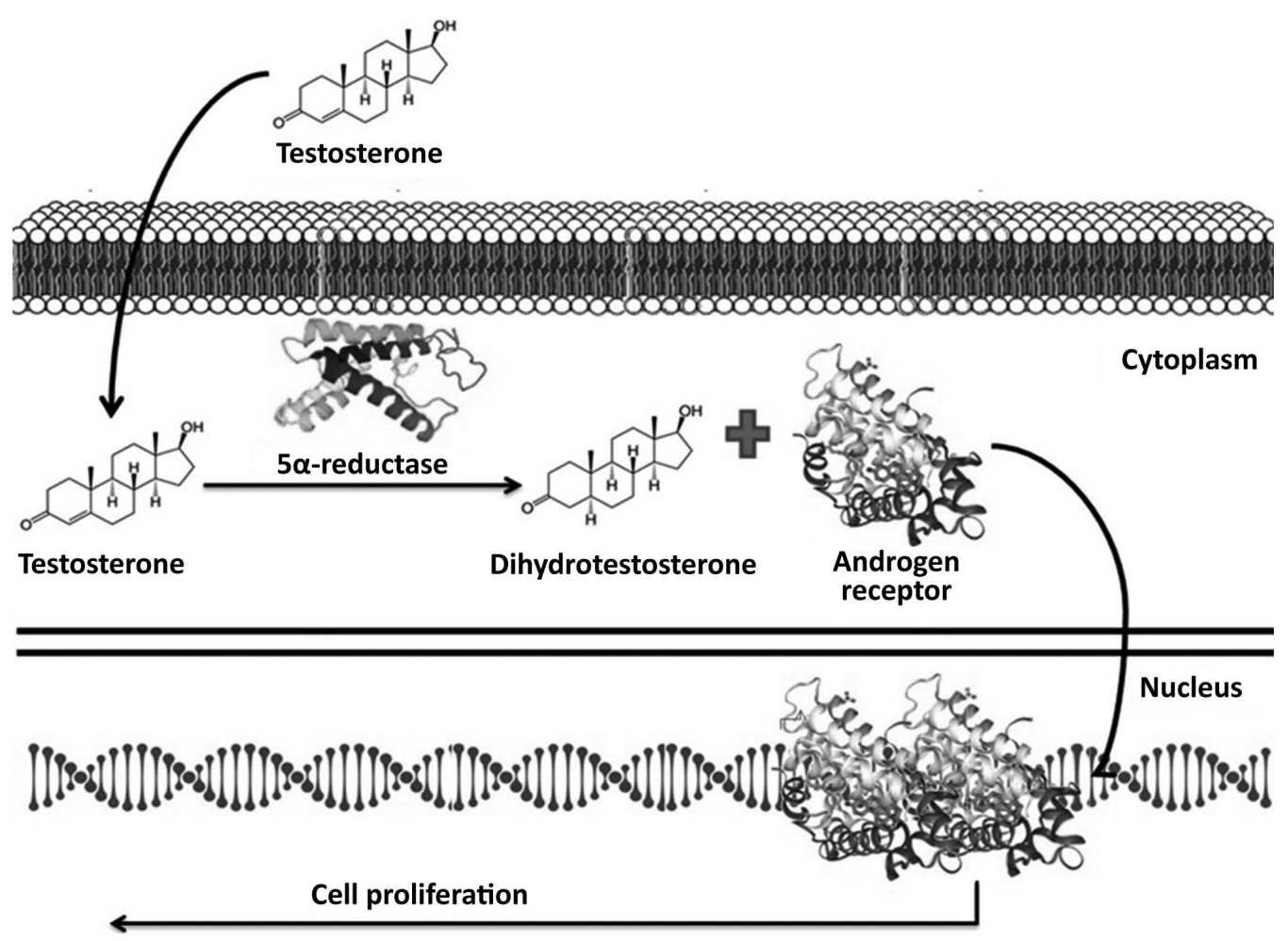

Figure 1. Androgen receptor signaling axis. Testosterone enters prostate cells, where it is reduced to DHT by the action of the steroid $5 \alpha$-reductase 2 . Binding of DHT to the AR generates conformational changes that enable the dimerization of the AR and the subsequent binding to the androgen-response elements of androgen-responsive genes promoting cell proliferation. DHT, dihydrotestosterone; AR, androgen receptor.

95\% confidence intervals (CIs), Bonferroni P-values and false discovery rates (FDRs) (23). The dominant model considered the analyzed phenotypes of Ala/Ala+Ala/Thrvs. Thr/Thr for the rs9282858 and Val/Val+Val/Leu vs. Leu/Leu for the rs523349 variants. On the other hand, the recessive genetic model considered the analyzed phenotypes Ala/Ala vs. Ala/Thr+Thr/Thr for the rs9282858 and Val/Val vs. Val/Leu+Leu/Leu for the rs523349 variants (29).

For the regression association study, a stepwise linear regression model (qthelp://org.sphinx.svsmanual. 8.8.3/doc/svsmanual/ftParts/logistic_regression.html) with recoded genotypes with the additive gene model $(\mathrm{DD}=2, \mathrm{Dd}=1$, $\mathrm{dd}=0$ ) was used. False discovery rate correction (FDR) was calculated to exclude spurious associations (qthelp://org.sphinx. svsmanual.8.8.3/doc/svsmanual/ftParts/general_statistics.html).

\section{Results}

Clinical characteristics of cases and controls enrolled in the present study. The present study included 201 participants classified as patients with PCa $(\mathrm{n}=101)$ and non-PCa subjects, including males without prostate abnormalities $(n=60)$ and subjects with BPH $(n=40)$. For patients with PCa, the median age (IQR) was 70 (range, 64.5-75) years. Thirty percent of patients had a history of prostate pathology, while the median prostate-specific antigen (PSA) value was 20.4 (IQR, 9.65-62.82); 20.8\% had type 2 diabetes mellitus (T2DM), and body mass index (BMI) calculations for this group found that $33.7 \%$ were a normal weight, $40.8 \%$ were overweight, and $22.4 \%$ had some degree of obesity. Gleason Grading was calculated according to the recommendations of the International
Society of Urological Pathology (ISUP) (30). A total of $62 \%$ of patients were classified as Gleason Grade Group 5, as they had tumors with Gleason scores of 9 and 10. The majority of patients (67\%) received androgen deprivation therapy (ADT), predominantly bicalutamide alone or in combination with other drugs, such as goserelin and leuprolide. Table I shows the detailed clinical variables of the patients with $\mathrm{PCa}$.

For the non-PCa subjects, the median age (IQR) was 58.8 (range, 48-67) years; $42.4 \%$ had a history of prostate pathology, while the median PSA value for subjects with BPH was $8.55 \mathrm{ng} / \mathrm{ml}$ (IQR, 5.12-17.71); 21\% had T2DM, and the BMI calculations for this group found that $23.1 \%$ were a normal weight, $44.9 \%$ were overweight, and the remaining $32.1 \%$ had some degree of obesity.

Table II summarizes the relevant data of the patients with PCa and non-PCa subjects enrolled in the present study. Notably, an association was identified between PCa and biomass exposure $(\mathrm{P}=0.012 ; \mathrm{OR}=2.89 ; \mathrm{CI}=1.21-6.88)$ and tobacco use $(\mathrm{P}=0.028 ; \mathrm{OR}=1.88 ; \mathrm{CI}=1.07-3.31)$, compared with controls.

Genotyping. Table III shows the HWE analysis for $\mathrm{PCa}$ cases and controls, as well as the genotype frequencies. The A49T variant was out of HWE equilibrium in the population analyzed, unlike the V89L variant, which was maintained in HWE.

Statistical analysis. The results of the association analysis were categorized according to the method used. In the present study, dominant and recessive gene models were used to perform analysis. No association was identified in any of the conditions 
Table I. Clinical characteristics of the enrolled patients with prostate cancer.

\begin{tabular}{lc} 
Clinical characteristics & $\begin{array}{c}\text { Prostate cancer } \\
\text { cases, } \mathrm{n}(\%)\end{array}$ \\
\hline ISUP grade group & $2(2.0)$ \\
Group 1 & $13(13.3)$ \\
Group 2 & $13(13.3)$ \\
Group 3 & $9(9.2)$ \\
Group 4 & $61(62.2)$ \\
Group 5 & $63(62.4)$ \\
Extracapsular invasion & $57(56.4)$ \\
Neurovascular invasion & $7(6.9)$ \\
Recurrence & $21(20.8)$ \\
Metastasis & $14(13.9)$ \\
Castration-resistance & \\
Androgen deprivation therapy & $22(32.8)$ \\
Bicalutamide & $9(13.4)$ \\
Bicalutamide + leuprolide & $11(16.4)$ \\
Bicalutamide + goserelin & $12(17.9)$ \\
Bicalutamide + orchiecthomy & $6(8.9)$ \\
Orchiectomy & $7(10.4)$ \\
Other &
\end{tabular}

${ }^{\mathrm{a}}$ Group 1, Gleason Score <6; Group 2, Gleason Score=7(3+4); Group 3, Gleason Score=7(4+3); Group 4, Gleason Score=8; Group 5, Gleason Score $=9$ and 10. bother treatments: Bicalutamide + leuprolide + orchiectomy, goserelin + leuprolide, zoledronic acid + leuprolide, goserelin, orchiectomy + docetaxel, and leuprolide + goserelin + ketoconazole + prednisolone. ISUP, International Society of Urological Pathology.

of the models or in the development of PCa (A49T variant) or in conferring a protective effect (V89L variant). Table IV presents the results obtained for the variants A49T and V89L after performing a statistical analysis using the dominance and recessiveness gene models, as well as the OR and 95\% CI range.

Clinical and genetic features association. The analysis between clinical and genetic features was conducted using V89L genotypes. No association was identified between genotyping and clinical variables, including PSA, ISUP Grade Group, or a history BPH. However, an association was identified between rs523349 and biomass exposure $(\mathrm{P}=0.013$; $\mathrm{OR}=3.17 ; \mathrm{CI}=1.23-8.17$ for the $\mathrm{G}$ risk allele, and $\mathrm{OR}=0.32$, $\mathrm{CI}=0.12-0.81$ for the $\mathrm{C}$ protective allele) using the dominant gene model (https://doi.org/10.5281/zenodo.3932702). There was an association between V89L and patients with metastasis (Val/Val vs. Leu/Leu+Val/Leu; P=0.048; OR=0.390; $\mathrm{CI}=0.142-1.073$; Table V).

\section{Discussion}

Previous studies that have used the Mexican population as a subject of study have reported an association between certain variants in the SDR5A2 gene and diseases, including pseudo hermaphroditism and hypospadias (31-34), but not PCa. The effect of the two analyzed variants is different according to the ethnic group of study. For example, homozygous subjects possessing the V89L variant ( Val/Val) may have a protective effect if its origin is from Asia, but subjects with this same phenotype may have an increased risk of developing PCa. Cancer is a complex set of diseases in which different risk factors serve a crucial role in its development, where the genetic background is only one of them.

Logistic regression is an essential tool used in many clinical applications, including in clinical prediction models (35), patient screening (36), and for the developing and validation of novel diagnostic models (37). The clinical importance of genotyping the genetic variants analyzed in the present study lies in predicting the behaviour of the metabolic AR pathway. Logistic regression may then be applied in clinical prediction models, to develop and validate novel diagnostic models, and to assess and predict the success of steroid 5 alpha-reductase 2 inhibitors (38).

In the present study, the participants enrolled were males with diagnosed PCa, males with other urological diseases, or men without any apparent urological condition that serve as healthy controls. PCa is more frequently diagnosed in the fifth decade of life; therefore, the statistical difference between the ages of PCa vs. non-PCa subjects in the present study was expected. The analysis of specific clinical variables revealed that $\mathrm{PCa}$ was associated with certain risk factors, including tobacco use and biomass exposure. It was found that the median PSA value derived from the PCa cases $(20.4 \mathrm{ng} / \mathrm{ml})$ was significantly higher than that for the non-PCa subjects $(8.5 \mathrm{ng} / \mathrm{ml})$ included in the present study $(\mathrm{P}<0.001)$, which is consistent with the results of previous studies $(39,40)$. It was reported that $125 / 973(12.8 \%)$ of participants had PSA values $>4 \mathrm{ng} / \mathrm{ml}$ and 55 (44\%) were diagnosed with PCa in a previous screening study conducted by part of our research group in the Northeast Mexican population (41).

A limitation of our work was the lack of availability of PSA values in healthy controls. This limitation is due to the fact that all participants were recruited as a convenience sample by the Urology Department and that non-PCa cases were men with BPH $(n=40)$ or persons classified as men without prostate abnormalities $(n=60)$. The association of the gene variants analyzed in this work was made by comparing PCa vs. total non-PCa subjects.

No association was identified between T2DM and prostate cancer development. However, the study subjects were only classified as diabetic or not, without accounting for their glucose levels or medications. A recent meta-analysis of 733 articles identifying 17 cohort studies that included 274,677 male patients suggested that diabetes may result in a poorer prognosis for males with $\mathrm{PCa}$, but was not associated with PCa development (42). Another independent study reported an increased risk of mortality with $\mathrm{PCa}$ in diabetics, but not an association between diabetes and the incidence of prostate cancer (43). This may be explained by the comorbidities associated with T2DM, including atherosclerosis and renal failure, as patients with T2DM and other comorbidities may have a poorer response to treatment. Two meta-analyses reported a relative low risk of develop $\mathrm{PCa}$ in patients with 
Table II. Demographic characteristics of patients with PCa $(n=101)$ and control subjects $(n=100)$.

\begin{tabular}{|c|c|c|c|c|}
\hline Demographic characteristic & PCa cases & Non-PCa cases & P-value & OR $(95 \% \mathrm{CI})$ \\
\hline Age, median years (IQR) & $70(64.5-75.0)$ & $58.8(48-67)$ & $9.22 \times 10^{-15}$ & $1.13(1.08-1.17)$ \\
\hline PSA, median ng/ml (IQR) & $20.4(9.65-62.82)$ & $8.55(5.12-17.71)$ & $8.29 \times 10^{-20}$ & $1.11(1.07-1.16)$ \\
\hline $\mathrm{BMI}$, median $\mathrm{kg} / \mathrm{m}^{2}$ & $27.02( \pm 4.33)$ & $27.84( \pm 5.52)$ & 0.271 & NS \\
\hline BMI <18.5 (\% underweight) & 3.1 & 0.0 & NA & NS \\
\hline BMI 18.5-24.9, \% & 33.7 & 23.1 & 0.612 & NS \\
\hline BMI 25-29.9, \% & 40.8 & 44.9 & 0.226 & NS \\
\hline $\mathrm{BMI}>30, \%$ & 22.4 & 32.1 & 0.486 & NS \\
\hline Type 2 diabetes mellitus, $\%$ & 20.8 & 21.0 & 0.732 & NS \\
\hline Arterial hypertension, \% & 38.6 & 33.0 & 0.694 & NS \\
\hline Alcohol intake, $\%$ & 57.4 & 64.0 & 0.182 & NS \\
\hline Smoking habit, \% & 60.4 & 43.0 & 0.028 & $1.88(1.07-3.31)$ \\
\hline Biomass exposure, $\%$ & 20.8 & 8.0 & 0.012 & $2.89(1.21-6.88)$ \\
\hline Family history of prostate cancer, $\%$ & 18.8 & 12.0 & 0.224 & NS \\
\hline Family history of other cancers, $\%$ & 33.7 & 29.0 & 0.603 & NS \\
\hline
\end{tabular}

PCa, prostate cancer; OR, odds ratio; CI, confidence interval; IQR, interquartile range; PSA, prostate-specific antigen; BMI, body mass index; $\mathrm{NA}$, not available; NS, not significant. $\mathrm{P}<0.05$ indicates a statistically significant difference.

Table III. Hardy-Weinberg equilibrium and genotype frequencies of A49T (rs9282858) and V89L (rs523349) variants in cases and controls.

\begin{tabular}{|c|c|c|c|c|c|}
\hline \multirow[b]{2}{*}{ Variant } & \multirow[b]{2}{*}{ Reference alleles } & \multicolumn{2}{|c|}{ Fisher's HWE P-value } & \multicolumn{2}{|c|}{ Genotype frequency } \\
\hline & & Cases & Controls & Cases $(\%)$ & Controls (\%) \\
\hline \multirow[t]{2}{*}{ A49T (rs9282858) } & {$[\mathrm{C} / \mathrm{T}]$} & $1.90 \mathrm{E}-06$ & 0.005 & TIT: 0.030 (3) & TIT: 0.010 (1) \\
\hline & & & & ClC: 0.970 (98) & ClC: 0.990 (97) \\
\hline \multirow[t]{3}{*}{ V89L (rs523349) } & {$[\mathrm{C} / \mathrm{G}]$} & 0.678 & 0.999 & $\mathrm{ClC}: 0.376$ (38) & ClC: 0.448 (44) \\
\hline & & & & ClG: 0.455 (46) & ClG: 0.439 (43) \\
\hline & & & & GIG: 0.168 (17) & GIG: 0.112 (11) \\
\hline
\end{tabular}

G, guanine; T, thymine, C, cytosine.

Table IV. Association analysis of A49T and V89L variants.

\begin{tabular}{|c|c|c|c|c|c|c|}
\hline \multirow[b]{2}{*}{ Variant } & \multirow[b]{2}{*}{ Genetic model } & \multirow[b]{2}{*}{$\chi^{2}$ FDR } & \multirow[b]{2}{*}{ OR $(95 \% \mathrm{CI})$} & & \multicolumn{2}{|c|}{ Allele frequency } \\
\hline & & & & & Cases & Controls \\
\hline \multirow[t]{2}{*}{ A49T (rs9282858) } & Dominant & 0.327 & $\mathrm{~T}, 2.97(0.30-29.05)$ & C, $0.34(0.03-3.29)$ & $\mathrm{T}, 0.03$ & $\mathrm{~T}, 0.01$ \\
\hline & Recessive & 0.327 & T, $2.97(0.30-29.05)$ & $\mathrm{C}, 0.34(0.03-3.29)$ & $\mathrm{C}, 0.97$ & C, 0.99 \\
\hline \multirow[t]{2}{*}{ V89L (rs523349) } & Dominant & 0.594 & G, $1.35(0.77-2.38)$ & $\mathrm{C}, 0.74(0.42-1.30)$ & $\mathrm{G}, 0.396$ & $\mathrm{G}, 0.332$ \\
\hline & Recessive & 0.511 & $\mathrm{G}, 1.60(0.71-3.62)$ & C, $0.62(0.28-1.41)$ & $\mathrm{C}, 0.604$ & $\mathrm{C}, 0.668$ \\
\hline
\end{tabular}

FDR, false discovery rate; OR, odds ratio; CI, confidence interval; G, guanine, T, thymine; C, cytosine.

T2DM $(44,45)$. Other studies have presented controversial results regarding this comorbidity (46-48). Previously, our research team identified an increased risk of developing PCa with Gleason Scores $>8$ in patients with high glucose levels (49).
Additionally, a significant difference $(\mathrm{P}=0.028)$ was reported between tobacco use in $\mathrm{PCa}$ patients and non-PCa subjects (60.4\% vs. $43 \%$, respectively). Several previous studies have reported tobacco use as a risk factor for developing PCa (50-52). Smokers have an increased risk of 
Table V. Analysis of rs523349 (V89L) genotypes and clinical features.

\begin{tabular}{|c|c|c|c|c|c|c|c|c|c|}
\hline \multirow[b]{2}{*}{ Genotype } & \multicolumn{2}{|c|}{ PSA } & \multicolumn{3}{|c|}{$\begin{array}{l}\text { Grade Gleason Group } \\
\text { ISUP classification }^{\mathrm{a}}\end{array}$} & \multicolumn{2}{|c|}{ Metastasis } & \multicolumn{2}{|c|}{$\begin{array}{c}\text { Benign Prostatic } \\
\text { Hyperplasia }\end{array}$} \\
\hline & Median ng/ml & P-value & $\leq 3$ & $\geq 4$ & P-value & $\%$ & P-value & $\%$ & P-value \\
\hline VV & 48.46 & 0.684 & 14.28 & 23.47 & 0.071 & 3.96 & 0.492 & 20.60 & 0.282 \\
\hline VL & 47.53 & & 33.67 & 12.24 & & 13.86 & & 18.50 & \\
\hline LL & 53.22 & & 14.28 & 2.04 & & 2.97 & & 3.30 & \\
\hline $\mathrm{VV}+\mathrm{VL}$ & 51.07 & 0.655 & 26.50 & 57.10 & 0.125 & 17.82 & 0.766 & 39.10 & 0.3040 \\
\hline LL & 47.53 & & 2.04 & 14.30 & & 2.97 & & 3.30 & \\
\hline VV & 51.75 & 0.134 & 14.30 & 47.90 & 0.125 & 3.96 & 0.048 & 20.60 & 0.635 \\
\hline $\mathrm{LL}+\mathrm{VL}$ & 48.46 & & 14.30 & 23.50 & & 16.83 & & 21.70 & \\
\hline
\end{tabular}

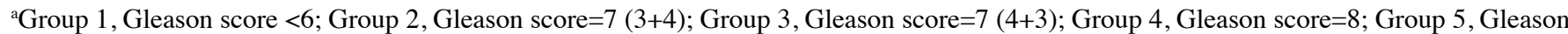
score $=9$ and 10. PSA, prostate-specific antigen; ISUP, International Society of Urological Pathology; VV, val/val; VL, val/leu; LL, leu/leu.

developing certain types of cancer, including lung cancer. However, it has been recognized that tobacco use may contribute toward the development of urological cancer, including prostate, bladder, ureters and kidney (50-53). This could be because chemical compounds released when tobacco is burned are distributed from the lung blood vessels to other tissues of the body.

When tobacco is burned, it produces carcinogenic compounds, mainly polycyclic aromatic hydrocarbons (PAHs) and nicotine-derived nitrosamines, including N'-nitrosonornicotine (NNN) and 4-(methylnitro samino)-1-(3-pyridyl)-1-butanone (NNK). In brief, tumorigenesis is caused by the formation of DNA adducts. These adducts generate mutations in key cell maintenance genes; the NNNs and NNKs may bind to acetylcholine receptors and promote events, including proliferation, growth, survival and cell migration (54). Furthermore, PAHs may bind to aryl hydrocarbon receptors (AHRs), which activate CYP1A1 and CYP1B1; the CYPs add an epoxide group to the PAHs, and these PHAs-epoxide complexes may bind to DNA to form adducts, which are crucial for tumorigenesis (55).

Notably, there was a significant difference between biomass exposure in patients with $\mathrm{PCa}$ and that in non-PCa subjects (20.8 vs. $8 \%$; $\mathrm{P}=0.012 ; \mathrm{OR}=2.89 ; \mathrm{CI}=1.21-6.88$ ). The Mexican population (mainly its Northern population) has a tradition for cooking grilled foods and performing other activities, such as working for petrochemical, steel and construction industries, that generate particles of sizes of $<10 \mu \mathrm{m}$, or being exposed to xenobiotic compounds, including polycyclic aromatic hydrocarbons (PAHs) (56). In the present study, the participants were surveyed to see with what frequency they cook their foods using wood. A previous study demonstrated how the exposure to this biomass is associated with the development of different types of cancer, primarily lung cancer (57). The mechanism by which the biomass compounds promote cancer development is unclear, but we hypothesize that it is associated with PAHs, primarilybenzo(a)pyrene. Benzo(a)pyrene serves a role in the formation of DNA adducts (58), specifically in the mutations involving the nucleotide change from $\mathrm{G}$ to $\mathrm{T}$ in the codons $157,158,248$, and 273 of the TP53 gene, with catastrophic consequences according to the IARC TP53 Database (R20, July 2019) (59). The two risk factors identified in the present study associated with benzo(a)pyrene were tobacco use and biomass exposure. The risk factor that was statistically significant following FDR correction was biomass exposure. Stepwise regression was a useful tool to identify this risk factor.

There are few studies on biomass exposure and PCa development, the most important of which is the Cancer Prevention Studio-II (CPS-II) of the American Cancer Society (60); however, the authors assessed risk factors for lung cancer, so the association with PCa was not investigated.

The A49T variant is associated with an increase in the activity of the 5-alpha reductase 2 enzyme, which converts testosterone to dihydrotestosterone (DHT). This more potent metabolite binds to the AR and results in the subsequent activation of target genes that promote cell proliferation, inhibition of apoptotic signals, and PSA overexpression.

A meta-analysis published in 2011 by Li et al (19) reported a significantly higher risk of developing stage III/IV PCa in homozygous variant subjects carrying the A49T variant (Thr/Thr allele), using a recessive gene model $(\mathrm{P}=0.0001$; $\mathrm{OR}=2.13$; $\mathrm{CI}=1.44-3.15$ ) (19). In the present study, no association was identified between SRD5A2 gene variants and PCa. The results demonstrated that $3 \%$ of subjects were carriers of the A49T (Thr/Thr allele) variant and it was not associated with $\mathrm{PCa}$ development $(\mathrm{P}=0.327)$. A limitation of the results of the present study is the HW disequilibrium, possibly due to the low frequency of this allele or the lack of heterozygous individuals in the sampled population $(61,62)$. Future studies should include an increased number of analyzed samples to verify these results.

Other ethnic groups, Ecuadorian, African American and Latin, had an association with the development of PCa and the A49T variant (Thr/Thr allele) $(16,63,64)$. By contrast, no association between this allele and $\mathrm{PCa}$ was identified in analyzes performed on Hispanic and Brazilian populations $(65,66)$. Table VI shows these previously reported genotyping studies and their association with $\mathrm{PCa}$ development. 
Table VI. Clinical effect of A49T (rs9282858) variant in other populations.

\begin{tabular}{|c|c|c|c|c|}
\hline Authors, year & Population & Effect & Genotype(s) & Refs. \\
\hline Makridakis et al, 1999 & African-American & Associated to cancer development & Thr/Thr & (16) \\
\hline Ribeiro et al, 2002 & Brazilian & Not associated with cancer development & Thr/Thr & (65) \\
\hline Pearce et al, 2008 & Hispanic/African-American & Not associated with cancer development & $\mathrm{Ala} / \mathrm{Thr}$ & (66) \\
\hline Paz-y-Miño et al, 2009 & Ecuadorian & Associated risk of prostate cancer & Thr/Thr vs. Ala/Thr & (63) \\
\hline Fang et al, 2017 & Latino & Associated with cancer development & $\mathrm{Thr} / \mathrm{Thr}$ & (64) \\
\hline
\end{tabular}

Although patients harboring the A49T variant $(\mathrm{Thr} / \mathrm{Thr}$ allele) were expected to have high PSA levels, the patients in the present study with the Thr/Thr genotype had PSA values of $5.23,8.00$, and $19.98 \mathrm{ng} / \mathrm{ml}$, possibly due to the tumor stage at the time of diagnosis. A more significant number of patients would be required to verify if there is any correlation between these two variables and PCa development in the Mexican-mestizo population.

As for the V89L variant, the homozygous allele variant Leu/Leu causes a decrease in the catalytic activity of steroid 5 alpha-reductase 2, while the homozygous wild-type Val/Val genotype has been associated with PCa development and higher Gleason stages.

In 1992, Batista et al (5) measured steroid 5-alphareductase 2 activity indirectly by quantifying testosterone metabolites in Afro-American and Asian individuals, finding differences attributed to enzyme activity levels; however, they did not take into account the genotypes of the analyzed subjects (8). This is due to the Leu/Leu allele, and a study in the Asian population reported this result with a protective effect by decreasing the risk of developing $\mathrm{PCa}$ (9).

In the present study, patients with this allele may be developing PCa due to other independent metabolic AR pathways, including damage repair DNA genes (67), PTEN (68) or TP53 (69). By contrast, the allele Leu/Leu was associated with cancer development in genotyping studies of European American (70) and Hispanic populations (71). Notably, this allele has been associated with PCa with Gleason scores $>8$ in the French population (72) and metastasis (73).

The present study identified a decreased statistical trend with regards to metastatic $\mathrm{PCa}$ when analyzing carriers of alleles Leu/Leu+Val/Leu vs. Val/Val ( $\mathrm{P}=0.048$; $\mathrm{OR}=0.390 ; \mathrm{CI}=0.142-1.073)$. To the best of our knowledge, there are no reports that directly determined the cause of this association, but we hypothesized that it may be due to the differential gene expression associated with metastasis in PCa, including EGR2, EGR3, MTA1, MYBL2 (74), SYNPO2, EGR3, RDX, FOXM1 (75), KLF6, MMP9 or $W N T 5 A$ (76). Additionally, when a naïve PCa is treated with ADT, its evolution to a metastatic state may be due to other transcriptional factors, including GATA2 or FOXA1 (77), fusion mutation TMPRSS2-ERG $(78,79)$ or AR variants (AR-V7) $(80,81)$.

SRD5A2, CYP17A1, and CYP19A1 are involved in the steroid metabolic (GO:0008202) and steroid biosynthetic processes (GO:0006694). In Mus musculus, benzo(a)pyrene has been associated with the Protein-Protein interaction
Network oxidation-reduction process (GO:0055114; Permanent link: http://bit.ly/2jIbOER) (82). The genes involved in this network participate in the cytochrome P450-mediated oxidation (Cyp17a1, Cyp19a1, Cyp1a2, Cyp21a1, Cyp3a11, Cyp3a13, Cyp3a16, Cyp3a25 and Cyp3a4la), and the reduction of oestrogens and androgens (Srd5a2, Akrld1, Hsd17bl and Hsd $3 b 4$ )

The Val/Val allele is more common in white Hispanic/non-Hispanic and Ecuadorian populations and it has been associated with $\mathrm{PCa}$ development; in the Mexican-mestizo population investigated in the present study, this association was not found. It has been seen that this allele may contribute toward worsening clinical prognosis associated with the overall survival, as was described in a previous study when comparing the different genetic variants and lower AR activity (83).

Table VII summarizes other genotyping studies of V89L and its potential associations with PCa development, metastasis, Gleason score, or protective effects against PCa $(9,63,70-73,84)$.

The analysis performed in the present study demonstrated that there was no association between the SRD5A2 rs523349 genotypes and Gleason scores $\geq 8$; however, there was a decreased tendency between patients with metastasis and rs523349 genotypes (Val/Val vs. Leu/Leu+Val/Leu; $\mathrm{P}=0.048$; $\mathrm{OR}=0.390 ; \mathrm{CI}=0.142-1.073$ ).

The clinical prognosis of the cohort of patients with $\mathrm{PCa}$ included in the present study was associated with 5-alpha reductase 2 variants. However, there are two main limitations: i) The present study included patients with localized and metastatic disease without discriminating the time of evolution, and ii) the type of ADT at the time of enrolment. The first-line treatment of ADT in clinical practice is the administration of bicalutamide, as the public medical care does not include new generation treatments in Mexico, including enzalutamide or abiraterone acetate.

Finally, regarding benign prostate diseases, a meta-analysis undertaken in 2017 by Zeng et al (85) found a risk of developing BPH in individuals carrying the $\mathrm{A} 49 \mathrm{~T}$ variant $(\mathrm{OR}=2.75$; $\mathrm{CI}=1.32-5.69)$, but this was not statistically significance $(\mathrm{P}=0.373)$. By contrast, the results of studies concerning the V89L variant and its association with the development of BPH and PSA changes have been contradictory $(86,87)$. A previous study reported that the $\mathrm{Val} / \mathrm{Leu}+\mathrm{Leu} / \mathrm{Leu}$ genotype $(\mathrm{P}=0.047$; $\mathrm{OR}=1.62 ; \mathrm{CI}=1.00-2.61$ ) was associated with the development of this benign condition, but not with the development of $\mathrm{PCa}(88)$. However, in another study, none of these genotypes were 
Table VII. Clinical effect of V89L (rs523349) variant in other populations.

\begin{tabular}{|c|c|c|c|c|}
\hline Author, year & Population & Effect & Genotype(s) & Refs. \\
\hline Makridakis et al, 1997 & Asian & Protective against cancer & Leu/Leu & $(9)$ \\
\hline Söderström et al, 2002 & Caucasian & Associated with metastasis & Leu/Leu & $(73)$ \\
\hline Loukola et al, 2004 & European-Americans & Associated with cancer development & Leu/Leu vs. Val/Leu ${ }^{\mathrm{a}}$ & (70) \\
\hline Salam et al, 2005 & Hispanic & Associated with cancer development & Leu/Leu & $(71)$ \\
\hline Cussenot et al, 2007 & French & Gleason Scores $>8$ & Leu/Leu & $(72)$ \\
\hline Torkko et al, 2008 & $\begin{array}{l}\text { Non-Hispanic White } \\
\text { Hispanic White }\end{array}$ & $\begin{array}{l}\text { Associated with cancer development } \\
\text { Associated with cancer development }\end{array}$ & $\begin{array}{l}\mathrm{Val} / \mathrm{Val}^{\mathrm{b}} \\
\mathrm{Val} / \mathrm{Val}^{\mathrm{c}}\end{array}$ & $(84)$ \\
\hline Paz-y-Miño et al, 2009 & Ecuadorian & Associated with cancer development & Val/Val & $(63)$ \\
\hline
\end{tabular}

associated with the development of BPH (85). In the future, a longitudinal analysis of Mexican patients with this type of benign disease should be performed to describe the frequency of the different genetic variants and to determine if they have a role in the prognosis of $\mathrm{PCa}$ as potential biomarkers for personalization of pharmacological treatments using 5 alpha-reductase enzyme inhibitors (87).

In conclusion, we identified the allelic frequencies of both the A49T and V89L variants of the steroid 5 alpha-reductase 2 gene in the Mexican population. No association was identified between either of the variants and the development of $\mathrm{PCa}$, but no increased risk of developing $\mathrm{PCa}$ was identified due to lifestyle factors, including the exposure to biomass and tobacco use. Furthermore, an association between V89L and biomass exposure was identified using the dominant gene model. Additionally, there was an association between V89L and patients with metastasis.

To the best of our knowledge, the present study was the first to screen the Mexican population for these variants, and one of the focussing on the Latino population. For these ethnic groups, molecular characterization of $\mathrm{PCa}$ is required to improve the understanding of this disease, and to determine if the results of molecular characterization studies may serve a role in the prognosis of PCa or as potential biomarkers for the personalization of pharmacological treatments.

\section{Acknowledgements}

The authors would like to thank the Dr María Carmen Barboza-Cerda (Laboratorio Nacional Biobanco, LANBIOBAN, Universidad Autónoma de Nuevo León, Monterrey, Mexico), for providing the equipment and facilities to perform certain experiments. They would also like to acknowledge Mr. Eduardo Coronado (Urology Service, 'Dr. José Eleuterio González' University Hospital, Universidad Autónoma de Nuevo León, Monterrey, Mexico) for his support in collecting the blood samples for the present study, and Dr. Sergio Lozano-Rodriguez (Office of the Vice Dean of Research, 'Dr. José Eleuterio González' University Hospital, Universidad Autónoma de Nuevo León, Monterrey, Mexico) for his review of the English language of this manuscript.

\section{Funding}

The present study was supported by the Program for Scientific and Technological Research 2019 of the Universidad Autónoma de Nuevo León, Mexico (PAICyT: SA763-19).

\section{Availability of data and materials}

The datasets used and/or analyzed during the current study are available from the corresponding author on reasonable request.

\section{Authors' contributions}

JRDB conducted the experiments, acquired, analyzed and interpreted the data; and drafted the manuscript. JRDB, HLGB, JFYL, LSGG and CNSD designed the study, conducted the experiments, analyzed, interpreted the data, and critically revised the manuscript. CNSD and AMRE made substantial contributions to the conception of the study, and drafted, and critically revised the manuscript. DHB, AMGB, GVM, MAOM and LSGG, as clinicians, selected the patients, performed the biopsies to obtain the samples, collected the clinical information from medical records, and contributed toward the design of the study. DAH and BSG assisted in technical support during the experimental work and were involved in the acquisition, analysis and interpretation of data. RGG and MNM, as pathologists, conducted the histopathological diagnoses of the patients. All authors read and approved the final manuscript.

\section{Ethics approval and consent to participate}

The protocol was approved by the Ethics and Research Committee of the School of Medicine (Universidad Autónoma de Nuevo León, Mexico; UR16-00007). Prior to blood extraction, written informed consent was obtained from the eligible participants.

\section{Patient consent for publication}

Not applicable. 


\section{Competing interests}

The authors declare that they have no competing interests.

\section{References}

1. Bray F, Ferlay J, Soerjomataram I, Siegel RL, Torre LA and Jemal A: Global cancer statistics 2018: GLOBOCAN estimates of incidence and mortality worldwide for 36 cancers in 185 countries. CA Cancer J Clin 68: 394-424, 2018.

2. Giovannucci E, Liu Y, Platz EA, Stampfer MJ and Willett WC: Risk factors for prostate cancer incidence and progression in the health professionals follow-up study. Int J Cancer 121: 1571-1578, 2007.

3. Feldman BJ and Feldman D: The development of androgen-independent prostate cancer. Nat Rev Cancer 1: 34-45, 2001.

4. Chandrasekar T, Yang JC, Gao AC and Evans CP: Mechanisms of resistance in castration-resistant prostate cancer (CRPC). Transl Androl Urol 4: 365-380, 2015.

5. Batista RL and Mendonca BB: Integrative and analytical review of the 5-alpha-reductase type 2 deficiency worldwide. Appl Clin Genet 13: 83-96, 2020.

6. Kokal M, Mirzakhani K, Pungsrinont T and Baniahmad A Mechanisms of androgen receptor agonist- and antagonist-mediated cellular senescence in prostate cancer. Cancers (Basel) 12: $1833,2020$.

7. Kregel S, Bagamasbad P, He S, LaPensee E, Raji Y, Brogley M, Chinnaiyan A, Cieslik M and Robins DM: Differential modulation of the androgen receptor for prostate cancer therapy depends on the DNA response element. Nucleic Acids Res 48: 4741-4755, 2020.

8. Ross RK, Bernstein L, Lobo RA, Shimizu H, Stanczyk FZ, Pike MC and Henderson BE: 5-alpha-reductase activity and risk of prostate cancer among Japanese and US white and black males. Lancet 339: 887-889, 1992.

9. Makridakis N, Ross RK, Pike MC, Chang L, Stanczyk FZ, Kolonel LN, Shi CY, Yu MC, Henderson BE and Reichardt JK A prevalent missense substitution that modulates activity of prostatic steroid 5alpha-reductase. Cancer Res 57: 1020-1022, 1997.

10. Ntais C, Polycarpou A and Ioannidis JP: SRD5A2 gene polymorphisms and the risk of prostate cancer: A meta-analysis. Cancer Epidemiol Biomarkers Prev 12: 618-624, 2003.

11. Reichardt JK, Makridakis N, Henderson BE, Yu MC, Pike MC and Ross RK: Genetic variability of the human SRD5A2 gene: Implications for prostate cancer risk. Cancer Res 55: 3973-3975, 1995.

12. Davis DL and Russell DW: Unusual length polymorphism in human steroid 5 alpha-reductase type 2 gene (SRD5A2). Hum Mol Genet 2: 820, 1993.

13. Ruijter E, van de Kaa C, Miller G, Ruiter D, Debruyne F and Schalken J: Molecular genetics and epidemiology of prostate carcinoma. Endocr Rev 20: 22-45, 1999.

14. Makridakis NM, di Salle E and Reichardt JK: Biochemical and pharmacogenetic dissection of human steroid 5 alpha-reductase type II. Pharmacogenetics 10: 407-413, 2000.

15. Hsing AW, Chen C, Chokkalingam AP, Gao YT, Dightman DA, Nguyen HT, Deng J, Cheng J, Sesterhenn IA, Mostofi FK, et al: Polymorphic markers in the SRD5A2 gene and prostate cancer risk: A population-based case-control study. Cancer Epidemiol Biomarkers Prev 10: 1077-1082, 2001

16. Makridakis NM, Ross RK, Pike MC, Crocitto LE, Kolonel LN, Pearce CL, Henderson BE and Reichardt JK: Association of mis-sense substitution in SRD5A2 gene with prostate cancer in African-American and Hispanic men in Los Angeles, USA. Lancet 354: 975-978, 1999.

17. Neslund-Dudas C, Bock CH, Monaghan K, Nock NL, Yang JJ, Rundle A, Tang D and Rybicki BA: SRD5A2 and HSD3B2 polymorphisms are associated with prostate cancer risk and aggressiveness. Prostate 67: 1654-1663, 2007.

18. Russell DW and Wilson JD: Steroid 5 alpha-reductase: Two genes/two enzymes. Annu Rev Biochem 63: 25-61, 1994.

19. Li X, Huang Y, Fu X, Chen C, Zhang D, Yan L, Xie Y, Mao Y and $\mathrm{Li} \mathrm{Y}$ : Meta-analysis of three polymorphisms in the steroid-5-alpha-reductase, alpha polypeptide 2 gene (SRD5A2) and risk of prostate cancer. Mutagenesis 26: 371-383, 2011.

20. Bentley AR, Callier S and Rotimi CN: Diversity and inclusion in genomic research: Why the uneven progress? J Community Genet 8: 255-266, 2017.
21. Moreno-Estrada A, Gignoux CR, Fernández-López JC, Zakharia F, Sikora M, Contreras AV, Acuña-Alonzo V, Sandoval K, Eng C, Romero-Hidalgo S, et al: Human genetics. The genetics of Mexico recapitulates Native American substructure and affects biomedical traits. Science 344: 1280-1285, 2014

22. Silva-Zolezzi I, Hidalgo-Miranda A, Estrada-Gil J, Fernandez-Lopez JC, Uribe-Figueroa L, Contreras A, Balam-Ortiz E, del Bosque-Plata L, Velazquez-Fernandez D, Lara C, et al: Analysis of genomic diversity in Mexican Mestizo populations to develop genomic medicine in Mexico. Proc Natl Acad Sci USA 106: 8611-8616, 2009.

23. Villarreal-Martínez A, Gallardo-Blanco H, Cerda-Flores R, Torres-Muñoz I, Gómez-Flores M, Salas-Alanís J, Ocampo-Candiani J and Martínez-Garza L: Candidate gene polymorphisms and risk of psoriasis: A pilot study. Exp Ther Med 11: 1217-1222, 2016

24. Patiño-García B, Arroyo C, Rangel-Villalobos H, Soto-Vega E, Velarde-Félix JS, Gabilondo F, Sandoval-Ramirez L and Figuera LE: Association between polymorphisms of the androgen and vitamin $D$ receptor genes with prostate cancer risk in a Mexican population. Rev Invest Clin 59: 25-31, 2007.

25. Martinez-Fierro ML, Garza-Veloz I, Rojas-Martinez A, Ortiz-Lopez R, Castruita-de la Rosa C, Ortiz-Castro Y, LazaldeRamos BP, Cervantes-Villagrana AR, Castañeda-Lopez ME, Gomez-Guerra L, et al: Positive association between vascular endothelial growth factor (VEGF) $-2578 \mathrm{C} / \mathrm{A}$ variant and prostate cancer. Cancer Biomark 13: 235-241, 2013.

26. Canto P, Benítez Granados J, Martínez Ramírez MA, Reyes E, Feria-Bernal G, García-García E, Tejeda ME, Zavala E, Tapia A, Rojano-Mejía D and Méndez JP: Genetic variants in ATP6 and ND3 mitochondrial genes are not associated with aggressive prostate cancer in Mexican-Mestizo men with overweight or obesity. Aging Male 19: 187-191, 2016.

27. Sanchez-Dominguez CN, Reyes-Lopez MA, Bustamante A, Cerda-Flores RM, Villalobos-Torres Mdel C, GallardoBlanco HL, Rojas-Martinez A, Martinez-Rodriguez HG, Barrera-Saldaña HA and Ortiz-Lopez R: The tumor necrosis factor alpha $(-308 \mathrm{~A} / \mathrm{G})$ polymorphism is associated with cystic fibrosis in Mexican patients. PLoS One 9: e90945, 2014

28. Jaramillo-Rangel G, Ortega-Martínez M, Cerda-Flores RM and Barrera-Saldaña HA: C3435T polymorphism in the MDR1 gene and breast cancer risk in northeastern Mexico. Int J Clin Exp Pathol 11: 904-909, 2018.

29. Zhao F, Song M, Wang Y and Wang W: Genetic model. J Cell Mol Med 20: 765, 2016.

30. Srigley JR, Delahunt B, Samaratunga H, Billis A, Cheng L, Clouston D, Evans A, Furusato B, Kench J, Leite K, et al: Controversial issues in Gleason and International Society of Urological Pathology (ISUP) prostate cancer grading: Proposed recommendations for international implementation. Pathology 51: 463-473, 2019.

31. CantoP, Vilchis F, Chávez B, Mutchinick O,Imperato-McGinley J, Pérez-Palacios G, Ulloa-Aguirre A and Méndez JP: Mutations of the 5 alpha-reductase type 2 gene in eight Mexican patients from six different pedigrees with 5 alpha-reductase-2 deficiency. Clin Endocrinol (Oxf) 46: 155-160, 1997.

32. Chávez B, Valdez E and Vilchis F: Uniparental disomy in steroid 5alpha-reductase 2 deficiency. J Clin Endocrinol Metab 85: 3147-3150, 2000

33. Vilchis F, Valdez E, Ramos L, García R, Gómez R and Chávez B: Novel compound heterozygous mutations in the SRD5A2 gene from 46, XY infants with ambiguous external genitalia. J Hum Genet 53: 401-406, 2008.

34. Shih EM and Graham JM Jr: Review of genetic and environmental factors leading to hypospadias. Eur J Med Genet 57: 453-463, 2014.

35. Zhou ZR, Wang WW, Li Y, Jin KR, Wang XY, Wang ZW, Chen YS, Wang SJ, Hu J, Zhang HN, et al: In-depth mining of clinical data: The construction of clinical prediction model with R. Ann Transl Med 7: 63, 2019.

36. Dong R, Jiang J, Zhang S, Shen Z, Chen G, Huang Y, Zheng Y and Zheng S: Development and validation of novel diagnostic models for biliary atresia in a large cohort of Chinese patients. EBioMedicine 34: 223-230, 2018.

37. Sun G, Nakayama Y, Dagdanpurev $S$, Abe S, Nishimura $H$, Kirimoto $\mathrm{T}$ and Matsui T: Remote sensing of multiple vital signs using a CMOS camera-equipped infrared thermography system and its clinical application in rapidly screening patients with suspected infectious diseases. Int J Infect Dis 55: 113-117, 2017. 
38. Shiota M, Fujimoto N, Yokomizo A, Takeuchi A, Kashiwagi E, Dejima T, Kiyoshima K, Inokuchi J, Tatsugami K and Eto M: The prognostic impact of serum testosterone during androgendeprivation therapy in patients with metastatic prostate cancer and the SRD5A2 polymorphism. Prostate Cancer Prostatic Dis 19: 191-196, 2016.

39. Kusuma Duarsa GW, Sari YA, Gde Oka AA, Santosa KB, Yudiana IW, Wisnu Tirtayasa PM, Putra Pramana IB and Kloping YP: Serum testosterone and prostate-specific antigen levels are major risk factors for prostatic volume increase among benign prostatic hyperplasia patients. Asian J Urol: Jun 7, 2020 (Epub ahead of print). doi: org/10.1016/j.ajur.2020.06.001

40. Golchin-Rad K, Mogheiseh A, Nazifi S, Ahrari Khafi MS, Derakhshandeh $\mathrm{N}$ and Abbaszadeh-Hasiri M: Changes in the serum prostatic biomarkers during the treatment of benign prostatic hyperplasia with a 5alpha-REDUCTASE inhibitor: Finasteride. Top Companion Anim Med 38: 100405, 2020.

41. Gomez-Guerra LS, Martinez-Fierro ML, Alcantara-Aragon V, Ortiz-Lopez R, Martinez-Villarreal RT, Morales-Rodriguez IB, Garza-Guajardo R, Ponce-Camacho MA and Rojas-Martinez A: Population based prostate cancer screening in north Mexico reveals a high prevalence of aggressive tumors in detected cases. BMC Cancer 9: 91, 2009.

42. Lee J, Giovannucci E and Jeon JY: Diabetes and mortality in patients with prostate cancer: A meta-analysis. Springerplus 5 : $1548,2016$.

43. Marrone MT, Selvin E, Barber JR, Platz EA and Joshu CE: Hyperglycemia, classified with multiple biomarkers simultaneously in men without diabetes, and risk of fatal prostate cancer. Cancer Prev Res (Phila) 12: 103-112, 2019.

44. Bansal D, Bhansali A, Kapil G, Undela K and Tiwari P: Type 2 diabetes and risk of prostate cancer: A meta-analysis of observational studies. Prostate Cancer Prostatic Dis 16: 151-158, S1, 2013.

45. Lin E, Garmo H, Van Hemelrijck M, Adolfsson J, Stattin P, Zethelius B and Crawley D: Association of type 2 diabetes mellitus and antidiabetic medication with risk of prostate cancer: A population-based case-control study. BMC Cancer 20: 551, 2020.

46. Tseng $\mathrm{CH}$. Metformin significantly reduces incident prostate cancer risk in Taiwanese men with type 2 diabetes mellitus. Eur J Cancer 50: 2831-2837, 2014.

47. Azoulay L, Dell'Aniello S, Gagnon B, Pollak M and Suissa S: Metformin and the incidence of prostate cancer in patients with type 2 diabetes. Cancer Epidemiol Biomarkers Prev 20: 337-344, 2011.

48. Häggström C, Van Hemelrijck M, Zethelius B, Robinson D, Grundmark B, Holmberg L, Gudbjörnsdottir S, Garmo H and Stattin P: Prospective study of Type 2 diabetes mellitus, anti-diabetic drugs and risk of prostate cancer. International journal of cancer Journal international du cancer 140: 611-617, 2017.

49. Garza-Guajardo R, Delgado-Enciso I, Melo-De-La-Garza A, Rodriguez-Sanchez I, Laura GL, Martinez-Fierro ML, Gómez-Guerra L, Gómez-Macías GS, Barboza-Quintana A, Guzmán-Esquivel J, et al: High fasting glucose, but not metabolic syndrome, is associated with elevated histologic aggressiveness in Mexican prostate cancer patients. Int J Clin Exp Pathol 9: 11951-11957, 2016

50. Plaskon LA, Penson DF, Vaughan TL and Stanford JL: Cigarette smoking and risk of prostate cancer in middle-aged men. Cancer Epidemiol Biomarkers Prev 12: 604-609, 2003.

51. Zu K and Giovannucci E: Smoking and aggressive prostate cancer: A review of the epidemiologic evidence. Cancer Causes Control 20: 1799-1810, 2009.

52. Huncharek M, Haddock KS, Reid R and Kupelnick B: Smoking as a risk factor for prostate cancer: A meta-analysis of 24 prospective cohort studies. Am J Public Health 100: 693-701, 2010.

53. How Tobacco Smoke Causes Disease: The Biology and Behavioral Basis for Smoking-Attributable Disease. In: A Report of the Surgeon General. Centers for Disease Control and Prevention, Atlanta, GA, 2010.

54. Xue J, Yang S and Seng S: Mechanisms of cancer induction by tobacco-specific NNK and NNN. Cancers (Basel) 6: 1138-1156, 2014.

55. Baird WM, Hooven LA and Mahadevan B: Carcinogenic polycyclic aromatic hydrocarbon-DNA adducts and mechanism of action. Environ Mol Mutagen 45: 106-114, 2005.
56. Zelikoff JT, Chen LC, Cohen MD and Schlesinger RB: The toxicology of inhaled woodsmoke. J Toxicol Environ Health B Crit Rev 5: 269-282, 2002.

57. IARC Working Group on the Evaluation of Carcinogenic Risk to Humans. Household Use of Solid Fuels and High-temperature Frying. Lyon (FR): International Agency for Research on Cancer; 2010. (IARC Monographs on the Evaluation of Carcinogenic Risks to Humans, No. 95.) 2, Studies of Cancer in Humans. Available from: https://www.ncbi.nlm.nih.gov/books/NBK385519/.

58. Li N, Luo HD, Jia YZ, Zhou N and Li YQ: Rapid determination of benzo(a)pyrene in processed meat and fish samples by second-derivative constant-energy synchronous fluorescence spectrometry. Food Addit Contam Part A Chem Anal Control Expo Risk Assess 28: 235-242, 2011

59. Bouaoun L, Sonkin D, Ardin M, Hollstein M, Byrnes G, Zavadil J and Olivier M: TP53 Variations in human cancers: New lessons from the IARC TP53 database and genomics data. Hum Mutat 37: 865-876, 2016.

60. Stellman SD, Demers PA, Colin D and Boffetta P: Cancer mortality and wood dust exposure among participants in the American Cancer Society Cancer Prevention Study-II (CPS-II). Am J Ind Med 34: 229-237, 1998.

61. Chen B, Cole JW and Grond-Ginsbach C: Departure from Hardy Weinberg Equilibrium and genotyping error. Front Genet 8: 167, 2017.

62. McQuillan R, Leutenegger AL, Abdel-Rahman R, Franklin CS, Pericic M, Barac-Lauc L, Smolej-Narancic N, Janicijevic B, Polasek O, Tenesa A, et al: Runs of homozygosity in European populations. Am J Hum Genet 83: 359-372, 2008.

63. Paz-y-Miño C, Witte T, Robles P, Llumipanta W, Diaz M and Arevalo M: Association among polymorphisms in the steroid 5alpha-reductase type II (SRD5A2) gene, prostate cancer risk, and pathologic characteristics of prostate tumors in an Ecuadorian population. Cancer Genet Cytogenet 189: 71-76, 2009.

64. Fang C, Guo ZQ, Chen XY, Liu TZ, Zeng XT and Wang XH: Relationship between SRD5A2 rs9282858 polymorphism and the susceptibility of prostate cancer: A meta-analysis based on 20 publications. Medicine (Baltimore) 96: e6791, 2017.

65. Ribeiro ML, Santos A, Carvalho-Salles AB and Hackel C: Allelic frequencies of six polymorphic markers for risk of prostate cancer. Braz J Med Biol Res 35: 205-213, 2002.

66. Pearce CL, Van Den Berg DJ, Makridakis N, Reichardt JK, Ross RK, Pike MC, Kolonel LN and Henderson BE: No association between the SRD5A2 gene A49T missense variant and prostate cancer risk: Lessons learned. Hum Mol Genet 17: 2456-2461, 2008.

67. Mateo J, Carreira S, Sandhu S, Miranda S, Mossop H, Perez-Lopez R, Nava Rodrigues D, Robinson D, Omlin A, Tunariu N, et al: DNA-Repair Defects and Olaparib in Metastatic Prostate Cancer. N Engl J Med 373: 1697-1708, 2015.

68. Ruscetti MA and Wu H: PTEN in prostate cancer. Prostate Cancer: 87-137, 2013.

69. Ecke TH, Schlechte HH, Schiemenz K, Sachs MD, Lenk SV, Rudolph BD and Loening SA: TP53 gene mutations in prostate cancer progression. Anticancer Res 30: 1579-1586, 2010.

70. Loukola A, Chadha M, Penn SG, Rank D, Conti DV, Thompson D, Cicek M, Love B, Bivolarevic V, Yang Q, et al: Comprehensive evaluation of the association between prostate cancer and genotypes/haplotypes in CYP17A1, CYP3A4, and SRD5A2. Eur J Hum Genet 12: 321-332, 2004.

71. Salam MT, Ursin G, Skinner EC, Dessissa T and Reichardt JK: Associations between polymorphisms in the steroid 5-alpha reductase type II (SRD5A2) gene and benign prostatic hyperplasia and prostate cancer. Urol Oncol 23: 246-253, 2005.

72. Cussenot O, Azzouzi AR, Nicolaiew N, Mangin P, Cormier L, Fournier G, Valeri A and Cancel-Tassin G: Low-activity V89L variant in SRD5A2 is associated with aggressive prostate cancer risk: An explanation for the adverse effects observed in chemoprevention trials using 5-alpha-reductase inhibitors. Eur Urol 52: 1082-1087, 2007.

73. Söderström T, Wadelius M, Andersson SO, Johansson JE, Johansson S, Granath F and Rane A: 5alpha-reductase 2 polymorphisms as risk factors in prostate cancer. Pharmacogenetics 12: 307-312, 2002.

74. LaTulippe E, Satagopan J, Smith A, Scher H, Scardino P, Reuter V and Gerald WL: Comprehensive gene expression analysis of prostate cancer reveals distinct transcriptional programs associated with metastatic disease. Cancer Res 62: 4499-4506, 2002. 
75. Chandran UR, Ma C, Dhir R, Bisceglia M, Lyons-Weiler M, Liang W, Michalopoulos G, Becich M and Monzon FA: Gene expression profiles of prostate cancer reveal involvement of multiple molecular pathways in the metastatic process. BMC Cancer 7: 64, 2007.

76. Stanbrough M, Bubley GJ, Ross K, Golub TR, Rubin MA, Penning TM, Febbo PG and Balk SP: Increased expression of genes converting adrenal androgens to testosterone in androgen-independent prostate cancer. Cancer Res 66: 2815-2825, 2006.

77. Obinata D, Takayama K, Takahashi S and Inoue S: Crosstalk of the androgen receptor with transcriptional collaborators: Potential therapeutic targets for castration-resistant prostate cancer. Cancers (Basel) 9: 22, 2017.

78. Squire JA: TMPRSS2-ERG and PTEN loss in prostate cancer. Nat Genet 41: 509-510, 2009.

79. Kiflemariam S, Mignardi M, Ali MA, Bergh A, Nilsson M and Sjoblom T: In situ sequencing identifies TMPRSS2-ERG fusion transcripts, somatic point mutations and gene expression levels in prostate cancers. J Pathol 234: 253-261, 2014.

80. Li H, Wang Z, Tang K, Zhou H, Liu H, Yan L, Guan W, Chen K, $\mathrm{Xu} \mathrm{H}$ and Ye Z: Prognostic value of androgen receptor splice variant 7 in the treatment of castration-resistant prostate cancer with next generation androgen receptor signal inhibition: A systematic review and meta-analysis. Eur Urol Focus 4: 529-539, 2018.

81. Markowski MC, Silberstein JL, Eshleman JR, Eisenberger MA Luo J and Antonarakis ES: Clinical utility of CLIA-Grade AR-V7 testing in patients with metastatic castration-resistant prostate cancer. JCO Precis Oncol: Oct 10, 2017 (Epub ahead of print). doi: 10.1200/PO.17.00127, 2017.

82. Szklarczyk D, Santos A, von Mering C, Jensen LJ, Bork P and Kuhn M: STITCH 5: Augmenting protein-chemical interaction networks with tissue and affinity data. Nucleic Acids Res 44: D380-D384, 2016
83. Shiota M, Fujimoto N, Yokomizo A, Takeuchi A, Itsumi M, Inokuchi J, Tatsugami K, Uchiumi T and Naito S: SRD5A gene polymorphism in Japanese men predicts prognosis of metastatic prostate cancer with androgen-deprivation therapy. Eur J Cancer 51: 1962-1969, 2015.

84. Torkko KC, van Bokhoven A, Mai P, Beuten J, Balic I, Byers TE, Hokanson JE, Norris JM, Barón AE, Lucia MS, et al: VDR and SRD5A2 polymorphisms combine to increase risk for prostate cancer in both non-Hispanic White and Hispanic White men. Clin Cancer Res 14: 3223-3229, 2008.

85. Zeng XT, Su XJ, Li S, Weng H, Liu TZ and Wang XH: Association between SRD5A2 rs523349 and rs9282858 polymorphisms and risk of benign prostatic hyperplasia: A meta-analysis. Front Physiol 8: 688, 2017.

86. Rył A, Rotter I, Grzywacz A, Małecka I, Skonieczna-Żydecka K, Grzesiak K, Słojewski M, Szylińska A, Sipak-Szmigiel O, Piasecka M, et al: Molecular analysis of the SRD5A1 and SRD5A2 genes in patients with benign prostatic hyperplasia with regard to metabolic parameters and selected hormone levels. Int J Environ Res Public Health 14: 1318, 2017.

87. Gu X, Na R, Huang T, Wang L, Tao S, Tian L, Chen Z, Jiao Y, Kang J, Zheng S, et al: SRD5A1 and SRD5A2 are associated with treatment for benign prostatic hyperplasia with the combination of $5 \alpha$-reductase inhibitors and $\alpha$-adrenergic receptor antagonists. J Urol 190: 615-619, 2013.

88. Choubey VK, Sankhwar SN, Carlus SJ, Singh AN, Dalela D, Thangaraj K and Rajender S: SRD5A2 gene polymorphisms and the risk of benign prostatic hyperplasia but not prostate cancer. Asian Pac J Cancer Prev 16: 1033-1036, 2015.

This work is licensed under a Creative Commons Attribution-NonCommercial-NoDerivatives 4.0 International (CC BY-NC-ND 4.0) License. 